\title{
COMPÓSITOS MAGNÉTICOS BASEADOS EM HIDROTALCITAS PARA A REMOÇÃO DE CONTAMINANTES ANIÔNICOS EM ÁGUA
}

\section{Leandro da Conceição e Sibele B. C. Pergher*}

Departamento de Química, Universidade Regional Integrada do Alto Uruguai e das Missões, Av. Sete de Setembro, 1621, 99700-000 Erechim - RS, Brasil

\section{Celso C. Moro}

Instituto de Química, Universidade Federal do Rio Grande do Sul, Av. Bento Gonçalves, 9500, 01540-970 Porto Alegre - RS, Brasil

Luiz C. A. Oliveira

Departamento de Química, Universidade Federal de Lavras, 37200-000 Lavras - MG, Brasil

Recebido em 16/1/06; aceito em 9/1/07; publicado na web em 24/7/07

\begin{abstract}
MAGNETIC COMPOSITES BASED ON HYDROTALCITES FOR REMOVAL OF ANIONIC CONTAMINANTS IN WATER. In this work the adsorption features of hydrotalcites $\left(\mathrm{Al}, \mathrm{Mg}-\mathrm{CO}_{3}\right)$ and the magnetic properties of iron oxides have been combined in a composite to produce a magnetic adsorbent. These magnetic composites can be used as adsorbents for anionic contaminants in water and subsequently removed from the medium by a simple magnetic process. The magnetic hydrotalcites were characterized by XRD, magnetization measurements, $\mathrm{N}_{2}$ adsorption isotherms and Mössbauer spectroscopy. These magnetic adsorbents show remarkable adsorption capacity for anionic contaminants in water.
\end{abstract}

Keywords: HDL/iron oxide composite; magnetic adsorbents; anionic contaminants.

\section{INTRODUÇÃO}

As hidrotalcitas são hidróxidos duplos lamelares com elevada capacidade de troca aniônica, sendo muito utilizadas como adsorventes de contaminantes ${ }^{1-5}$. A aplicação de compósitos magnéticos para resolver problemas ambientais tem recebido considerável atenção nos últimos anos ${ }^{6-8}$. Compósitos magnéticos podem ser usados para adsorver contaminantes de efluentes industriais e, após a adsorção, podem ser separados por um simples processo magnético. Nosso grupo vem desenvolvendo compósitos magnéticos com elevada área superficial e alta capacidade de adsorção, tais como argilas/óxido de ferro, carvão ativado/óxido de ferro ${ }^{9} \mathrm{e}$ mais recentemente zeólitas/óxido de ferro ${ }^{10}$.

Neste trabalho, as propriedades de adsorção da hidrotalcita foram combinadas com as propriedades magnéticas do óxido de ferro para produzir adsorventes magnéticos. Estes adsorventes apresentam a vantagem de serem facilmente removidos do meio, após a adsorção dos contaminantes, por um simples processo de separação magnética. Os materiais preparados foram testados na remoção do corante aniônico vermelho reativo e de ânions cromato.

\section{Hidróxido duplos lamelares}

Os hidróxidos duplos lamelares (HDLs) sintéticos foram preparados pela primeira vez em 1933 por Feitknetch ${ }^{6}$, pela precipitação controlada de soluções aquosas contendo cátions metálicos com uma base. Apesar de não serem abundantes na natureza, a síntese dos hidróxidos duplos lamelares em laboratórios é extremamente fácil. Estes compostos são representados pela seguinte fórmula ge$\mathrm{ral}^{11,12}$ (Tabela 1):

$\left[\mathrm{M}^{+2}{ }_{1-\mathrm{x}} \mathrm{M}_{\mathrm{x}}^{+3}(\mathrm{OH})_{2}\right]^{+\mathrm{x}} \mathrm{A}_{\mathrm{x} / \mathrm{m}}^{-\mathrm{m}} \cdot \mathrm{nH}_{2} \mathrm{O}$
Tabela 1. Minerais naturais e sua composição

\begin{tabular}{lcccc}
\hline \multicolumn{2}{c}{ Cátions } & Ânions & \multicolumn{2}{c}{ Nome do Mineral } \\
\hline $\mathrm{M}^{\mathrm{II}}$ & $\mathrm{M}^{\mathrm{II}}$ & $\mathrm{N}^{-n}$ & Romboédrico & Hexagonal \\
\hline $\mathrm{Mg}$ & $\mathrm{Al}$ & $\mathrm{CO}_{3}^{-2}$ & Hidrotalcita & Manasita \\
$\mathrm{Mg}$ & $\mathrm{Al}$ & $\mathrm{OH}^{-}$ & Meixnerita & - \\
$\mathrm{Mg}$ & $\mathrm{Cr}$ & $\mathrm{CO}_{3}^{-2}$ & Stichita & Barbetonita \\
$\mathrm{Mg}$ & $\mathrm{Fe}$ & $\mathrm{CO}_{3}^{-2}$ & Pirourita & Sjogrenita \\
$\mathrm{Mg}$ & $\mathrm{Fe}$ & $\mathrm{Cl}^{-}$ & Iowaita & - \\
$\mathrm{Mg}$ & $\mathrm{Mn}$ & $\mathrm{CO}_{3}^{-2}$ & Desautelsita & - \\
$\mathrm{Mg}, \mathrm{Fe}$ & $\mathrm{Al}$ & $\mathrm{Cl}^{-}$ & Cloromagalumita & - \\
$\mathrm{Ni}$ & $\mathrm{Al}$ & $\mathrm{CO}_{3}^{-2}$ & Eardliyita & Takovita \\
$\mathrm{Ni}$ & $\mathrm{Fe}$ & $\mathrm{CO}_{3}^{-2}$ & Reevesita & honesita \\
\hline
\end{tabular}

onde: $\mathrm{M}^{+2}$ representa um cátion metálico divalente; $\mathrm{M}^{+3}$, um cátion trivalente; $\mathrm{A}^{-\mathrm{m}}$, um ânion intercalado com carga $\mathrm{m} ; \mathrm{x}$, a razão entre os cátions di e trivalentes; $n$, o número de mols de água

Para melhor compreender a estrutura dos HDLs, podemos, interpretá-la como derivada da brucita $\left(\mathrm{Mg}(\mathrm{OH})_{2}\right)$, onde os íons $\mathrm{Mg}^{2+}$ são coordenados octaedricamente por grupos hidroxila com os octaedros compartilhando arestas, formando camadas neutras infinitas, que são mantidas empilhadas através de ligações de hidrogênio, como representado na Figura 1. Quando alguns íons $\mathrm{Mg}^{2+}$ são isomorficamente substituídos por íons trivalentes (por exemplo $\mathrm{Al}^{3+}$ ), uma carga residual positiva é gerada na lamela. Esta carga positiva gerada é compensada por ânions intercalados entre as lamelas, empilhando-as umas sobre as outras resultando, desta forma, na estrutura da hidrotalcita ${ }^{11}$ (Figura 2).

Vários compostos aniônicos, orgânicos e inorgânicos podem ocupar esta região interlamelar. A estrutura formada pelo compartilhamento de camadas positivamente carregadas, com ânions ocupando a região intermolecular, é comum a todos os hidróxidos duplos lamelares ${ }^{13}$.

Uma grande quantidade de HDLs naturais e sintéticos conten- 


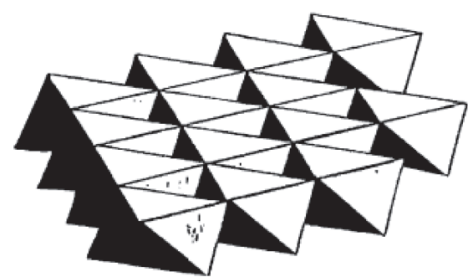

Figura 1. Estrutura esquemática da brucita $\left(\mathrm{Mg}(\mathrm{OH})_{2}\right)$

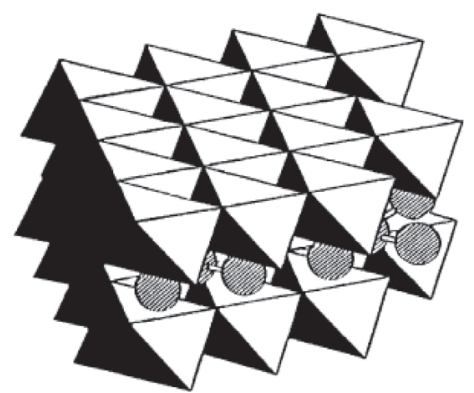

Figura 2. Esquema tridimensional da estrutura das argilas aniônicas

do cátions metálicos vem sendo estudados; os cátions divalentes mais comuns são os de $\mathrm{Mg}, \mathrm{Mn}, \mathrm{Fe}, \mathrm{Co}, \mathrm{Ni}, \mathrm{Cu}, \mathrm{Zn}$ e $\mathrm{Ca}$ e os cátions trivalentes são os de $\mathrm{Al}, \mathrm{Cr}, \mathrm{Mn}, \mathrm{Fe}, \mathrm{Co}$ e Ni. Várias combinações de cátions di e trivalentes foram utilizadas para a síntese de HDLs, por diferentes autore ${ }^{13}$ variando também os métodos de síntese. Os cátions metálicos utilizados para estas sínteses de HDLs devem possuir coordenação octaédrica e raio iônico na faixa de $0,50-0,74 \AA$, para que ocorra a formação da estrutura.

A Tabela 2 apresenta várias combinações que já foram estudadas e produziram hidróxidos duplos lamelares.

Tabela 2. Combinações de cátions divalentes com trivalentes na formação de HDLs

\begin{tabular}{lccccccccc}
\hline Cátions & \multicolumn{1}{c}{ Divalentes } \\
Trivalentes & $\mathrm{Mg}$ & $\mathrm{Ni}$ & $\mathrm{Zi}$ & $\mathrm{Cu}$ & $\mathrm{Co}$ & $\mathrm{Mn}$ & $\mathrm{Fe}$ & $\mathrm{Ca}$ & $\mathrm{Li}^{*}$ \\
\hline $\mathrm{Al}$ & $\mathrm{X}$ & $\mathrm{X}$ & $\mathrm{X}$ & $\mathrm{X}$ & $\mathrm{X}$ & $\mathrm{X}$ & $\mathrm{X}$ & $\mathrm{X}$ & $\mathrm{X}$ \\
$\mathrm{Fe}$ & $\mathrm{X}$ & $\mathrm{X}$ & & & & & & & \\
$\mathrm{Cr}$ & $\mathrm{X}$ & $\mathrm{X}$ & $\mathrm{X}$ & $\mathrm{X}$ & & & & & \\
$\mathrm{Co}$ & & $\mathrm{X}$ & & & $\mathrm{X}$ & & & & \\
$\mathrm{Mn}$ & & & & & & $\mathrm{X}$ & & & \\
$\mathrm{Ni}$ & & $\mathrm{X}$ & & & & & & & \\
$\mathrm{Sc}$ & $\mathrm{X}$ & & & & & & & & \\
$\mathrm{Ga}$ & & & & & & $\mathrm{X}$ & & & \\
$\mathrm{Ti} * *$ & & & & & $\mathrm{X}$ & & & & \\
\hline
\end{tabular}

*monovalente, **tetravalente.

A cristalinidade do material depende muito da razão entre os cátions di e trivalentes $\left(\mathrm{M}^{+2} / \mathrm{M}^{+3}\right)$ que pode variar em uma faixa de 1 a 8 , o que corresponde na fórmula geral de $0,14<x<0,5$. Esta razão $\left(\mathrm{M}^{+2} / \mathrm{M}^{+3}\right)$ está diretamente relacionada com a densidade de carga na lamela do HDL e, conseqüentemente, com as propriedades de troca iônica. A redução nesta razão (ou aumento da densidade de carga) dificulta a cinética do processo de troca e o aumento da razão diminui a capacidade total de troca aniônica do material ${ }^{13}$.

Existem diferentes espécies aniônicas que podem compensar a carga positiva da lamela. O carbonato é muito utilizado, pois o uso de outros ânions acaba também contaminado com $\mathrm{CO}_{2}$ presente nas soluções aquosas ${ }^{6}$. Algumas espécies aniônicas são relatadas na literatura e podem ser inorgânicas ou orgânicas ${ }^{14,15}$ : haletos $\left(\mathrm{F}^{-}, \mathrm{Cl}^{-}\right.$, $\mathrm{Br}, \mathrm{I}-$ ); oxo-ânions $\left(\mathrm{CO}_{3}^{-2}, \mathrm{NO}_{3}^{-}, \mathrm{SO}_{4}^{-2}, \mathrm{CrO}_{4}^{-2}\right)$; ânions complexos $\left(\left[\mathrm{Fe}(\mathrm{CN})_{6}\right]^{-4},\left[\mathrm{NiCl}_{4}\right]^{-2}\right)$; polioxo-metalatos $\left(\mathrm{V}_{10} \mathrm{O}^{-6}{ }_{28}, \mathrm{Mo}_{7} \mathrm{O}^{-6}{ }_{24}\right) \mathrm{e}$ ânions orgânicos (alquilsulfatos, carboxilatos, porfirinas).

Os HDLs podem apresentar uma grande variedade de aplicações dependendo de suas propriedades (composição, cristanilidade, estabilidade térmica e outras propriedades físico-químicas). Entre as aplicações mais exploradas pode-se citar o uso como catalisadores heterogêneos ${ }^{16-18}$, adsorventes ${ }^{2-19}$, trocadores aniônicos ${ }^{19}$ e em aplicações farmacêuticas ${ }^{22-24 .}$

A troca aniônica ocorre quando os aniôns intercalados no material precursor apresentam interações eletrostáticas fracas com a lamela. O grau de troca depende da tendência de substituição do ânion interlamelar e dos ânions a serem trocados, que é determinado pela densidade de carga de cada ânion. Neste caso, quanto maior a densidade de carga do ânion, maior será a interação eletrostática do mesmo com as lamelas. Entretanto, quando ânions orgânicos estão envolvidos, as interações entre as cadeias carbônicas irão influenciar e análises levando em consideração somente à densidade de carga não podem ser aplicadas.

A remoção de ânions de uma solução por HDLs usualmente ocorre pela combinação de dois processos, troca aniônica e adsorção. Em alguns casos o processo de adsorção é pouco satisfatório, especialmente para ânions inorgânicos, pois apresentam uma tendência muito pequena de serem adsorvidos. Alguns exemplos do processo de remoção através da troca aniônica incluem o tratamento de água para remoção de compostos de $\mathrm{Cr}$ (VI) e remoção de fosfatos ${ }^{25,26}$.

\section{PARTE EXPERIMENTAL}

A hidrotalcita empregada foi sintetizada pelo procedimento de co-precipitação com $\mathrm{pH}$ variável, utilizando as soluções de cátions: $\mathrm{Mg}\left(\mathrm{NO}_{3}\right)_{2}$ e $\mathrm{Al}\left(\mathrm{NO}_{3}\right)_{3}$ (razão $\mathrm{Mg} / \mathrm{Al}$ de 3:1) e a solução de ânions de $\mathrm{Na}_{2} \mathrm{CO}_{3}^{25}$

Os compósitos foram preparados através de uma suspensão de hidrotalcita $(0,5 \mathrm{~g})$ em $400 \mathrm{~mL}$ de uma solução de $\mathrm{FeCl}_{3} \cdot 6 \mathrm{H}_{2} \mathrm{O}$ $(0,5 \mathrm{~g})$ e $\mathrm{FeSO}_{4} \cdot 7 \mathrm{H}_{2} \mathrm{O}(1,2 \mathrm{~g})$ a $70{ }^{\circ} \mathrm{C}$. Uma solução de $\mathrm{NaOH}$ (30 mL, $5 \mathrm{~mol} / \mathrm{L})$ foi adicionada lentamente para que ocorresse a precipitação do óxido de ferro. Da mesma forma, o óxido de ferro pode ser sintetizado independentemente. A quantidade de hidrotalcita utilizada foi ajustada para se obter uma razão em massa de HDL:óxido de ferro de 1:1. Os materiais obtidos foram secos a $70{ }^{\circ} \mathrm{C}$ por $18 \mathrm{~h}$.

Os materiais preparados, bem como a hidrotalcita de partida, foram caracterizados por diversas técnicas complementares: difratometria de raios-X, análise textural por adsorção de $\mathrm{N}_{2}$, espectroscopia Mössbauer, microscopia eletrônica de varredura e espectroscopia no infravermelho.

As análises de difração de raios- $X$ foram realizadas em um Diffraktometer modelo D5000 (Siemens) utilizando filtro de Ni e radiação $\mathrm{Cu}-\mathrm{k} \alpha(\lambda=1,54 \AA$ ̊ $)$.

As medidas de espectroscopia Mössbauer foram realizadas com uma fonte de ${ }^{57} \mathrm{Co} / \mathrm{Rh}$ na temperatura do $\mathrm{N}_{2}$ líquido e calibrado com $\alpha$-Fe.

As medidas de magnetização foram realizadas com um magnetômetro portátil com um campo fixo de $0,3 \mathrm{~T}$.

A caracterização textural dos materiais foi feita utilizando um Autosorb-1 da Quantachrome.

As micrografias por microscopia eletrônica de varredura foram obtidas em um MEV SSZ 550 Shimadzu. As amostras foram previamente metalizadas com uma fina camada de ouro.

As isotermas de adsorção foram obtidas em um sistema de batelada com $10 \mathrm{mg}$ dos compósitos em $10 \mathrm{~mL}$ de soluções padrões de um corante aniônico (vermelho reativo) e de dicromato $(50,100,250,500$ e $1000 \mathrm{mg} / \mathrm{L})$. Todas as soluções foram mantidas por $24 \mathrm{~h}$ a $28 \pm 2{ }^{\circ} \mathrm{C}$ com um banho de temperatura controlada e 
pH ajustado com $\mathrm{HCl}$ diluído e/ou $\mathrm{NaOH}$ diluído $(\mathrm{pH}=4,7$ e 9). As concentrações do corante $(\lambda=540 \mathrm{~nm})$ ou do cromato $(\lambda=370 \mathrm{~nm})$ foram determinadas em um espectrômetro de UVvisível (Perkinelmer Lambda EZ 150).

\section{RESULTADOS E DISCUSSÃO}

\section{Caracterização dos materiais}

Os compósitos foram preparados pela precipitação do hidróxido ou óxido de ferro na superfície da hidrotalcita. Após o preparo, os compósitos mostraram propriedades magnéticas quando testados com um imã de $0,3 \mathrm{~T}$, mostrando que todo o material é completamente atraído pelo imã (Figura 3).

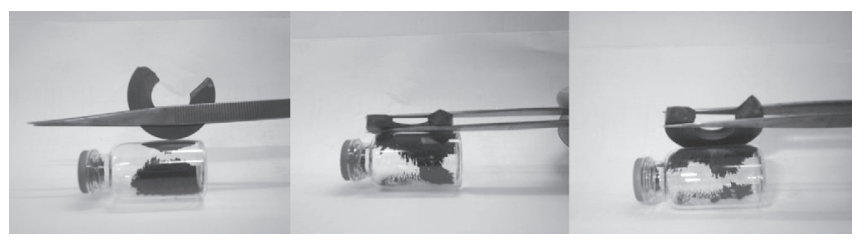

Figura 3. Fotografias do processo de atração do compósito HDL: óxido de ferro

A análise de difração de raios-X da hidrotalcita e do compósito (Figura 4) mostram um difratograma típico de $\mathrm{Al}, \mathrm{Mg}$ - hidrotalcita, depois da incorporação do óxido de ferro somente a fase óxido é observada. A Tabela 3 compara os resultados obtidos neste trabalho com os obtidos na literatura ${ }^{26}$. Comprova-se que a fase sintetizada é uma hidrotalcita de alta cristalinidade; ainda pode-se concluir, pela intensidade e largura dos picos, que o material se apresenta bem organizado e com empilhamento das lamelas. Observam-se alguns sinais de baixa intensidade que podem ser devidos à presença de óxidos formados.

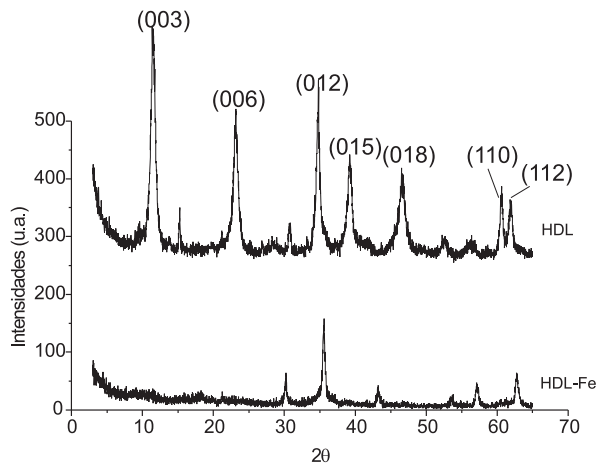

Figura 4. Difratograma de raios- $X$ da hidrotalcita de partida (HDL) e do compósito (HDL-Fe)

Tabela 3. Espaçamentos interlamelares para a hidrotalcita

\begin{tabular}{lcccccc}
\hline \multicolumn{2}{l}{ Dados obtidos da Figura 3 } & \multicolumn{4}{c}{ Dados da literatura } \\
$2 \theta$ & $\mathrm{d}(\mathrm{nm})$ & $\mathrm{I} / \mathrm{I}_{\mathrm{o}}$ & $2 \theta$ & $(\mathrm{hkl})$ & $\mathrm{d}(\mathrm{nm})$ & $\mathrm{I} / \mathrm{I}_{\mathrm{o}}$ \\
\hline 11,47 & 0,770 & 100 & 11,51 & $(003)$ & 0,769 & 100 \\
23,27 & 0,382 & 66 & 22,92 & $(006)$ & 0,388 & 70 \\
34,74 & 0,258 & 78 & 34,77 & $(012)$ & 0,258 & 20 \\
39,19 & 0,229 & 46 & 39,16 & $(015)$ & 0,230 & 20 \\
46,44 & 0,195 & 41 & 46,32 & $(018)$ & 0,196 & 20 \\
52,29 & 0,175 & 13 & 52,27 & - & 0,175 & 10 \\
56,46 & 0,163 & 12 & 55,70 & - & 0,165 & 10 \\
60,59 & 0,153 & 33 & 60,51 & $(110)$ & 0,153 & 20 \\
61,82 & 0,150 & 33 & 61,85 & $(113)$ & 0,150 & 20 \\
\hline
\end{tabular}

Após a incorporação do óxido de ferro, observa-se somente a fase óxido, provavelmente devido ao alto conteúdo de óxido incorporado. Uma hipótese do que pode estar acontecendo é que, como para a análise realizada foi utilizado um ânodo de $\mathrm{Cu}$ e filtro de $\mathrm{Ni}$, o ferro da superfície da hidrotalcita estaria absorvendo uma grande quantidade dos raios- $\mathrm{X}$, difratando somente poucos raios correspondentes ao óxido do ferro. Desta forma, não estaríamos observando os picos característicos da hidrotalcita original. Para evitar o problema, este tipo de análise deve ser realizado usando raios $\mathrm{X}$ provenientes de um ânodo de $\mathrm{Co}$, onde a absorção de raios $\mathrm{X}$ pelo Fe seria bem menor. Não podemos ainda descartar a possibilidade de que no processo de incorporação de Fe estivesse ocorrendo uma destruição parcial da estrutura da hidrotalcita.

Através das isotermas de adsorção de nitrogênio calcularamse as áreas superficiais BET. Os materiais apresentaram áreas BET de 106,1 e $46,4 \mathrm{~m}^{2} / \mathrm{g}$ para o HDL e HDL:óxido de ferro, respectivamente. Observa-se um decréscimo de área no compósito magnético quando comparado com a hidrotalcita. A principal razão para esta redução de área é o fato da hidrotalcita magnética possuir óxido de ferro, que tem uma área superficial muito menor quando comparada à hidrotalcita.

O espectro de Mössbauer, que auxilia na identicação das fases de ferro no compósito, está representado na Figura 5 e para o compósito HDL-Fe apresenta sinais típicos de fases de ferro do tipo oxi-hidróxido (por exemplo, goethita). Uma análise qualitativa do espectro sugere que o material formado é de baixa cristalinidade e formado por uma mistura de óxidos de ferro, sendo que o espectro mostra claramente a presença da fase magnética, magnetita $\left(\mathrm{Fe}_{3} \mathrm{O}_{4}\right)$, o que está de acordo com os resultados de difração de raios-X. Os dupletos centrais estão provavelmente relacionados ao superparamagnetismo apresentado por materiais com pequenos tamanhos de partícula. Para a obtenção de mais informações deverão ser realizadas medidas Mössbauer a temperatura do nitrogênio líquido, para eliminação do superparamagnetismo.

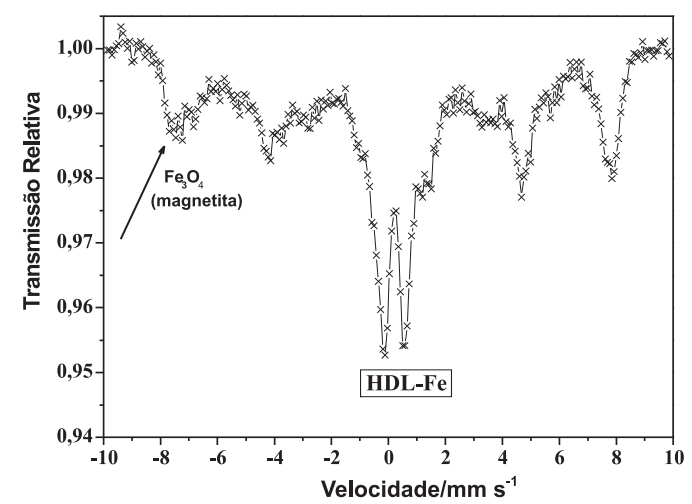

Figura 5. Espectro de Mössbauer para o compósito HDL:óxido de Fe

As micrografias de MEV (microscopia eletrônica de varredura) do compósito magnético HDL-Fe e da pura hidrotalcita HDL são apresentadas na Figura 6. A Figura 6a mostra uma visão geral do compósito, onde se observa o óxido de ferro (forma esponjosa, parecendo couve-flor) depositado na superfície da hidrotalcita, confirmando a presença do ferro na superfície. A Figura $6 \mathrm{~b}$ mostra detalhes da hidrotalcita pura.

Os resultados de espectroscopia infravermelha são apresentados na Figura 7. A banda de adsorção a $\sim 3500 \mathrm{~cm}^{-1}$, presente na hidrotalcita, é atribuída às vibrações de estiramento da ligação $\mathrm{H}-\mathrm{O}$ dos grupos $\mathrm{OH}$ na camada de hidróxidos tipo brucita ${ }^{26}$. A presença de um ombro a $3000 \mathrm{~cm}^{-1}$ é atribuída a ligações de hidrogênio entre a água e o ânion na intercamada ${ }^{27}$; uma banda de vi- 


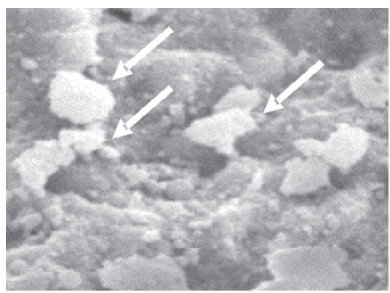

(a)

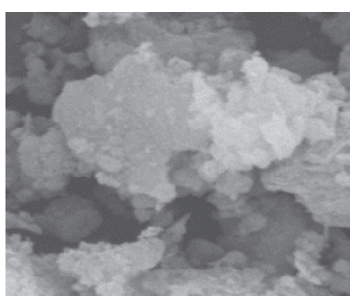

(b)
Figura 6. Micrografias do compósito $H D L-F e(a)$ e da hidrotalcita pura HDL (b)

bração da água aparece em $1600 \mathrm{~cm}^{-1}$ e a intensidade destas duas bandas depende do tipo de ânion e das quantidades de água interlamelar.

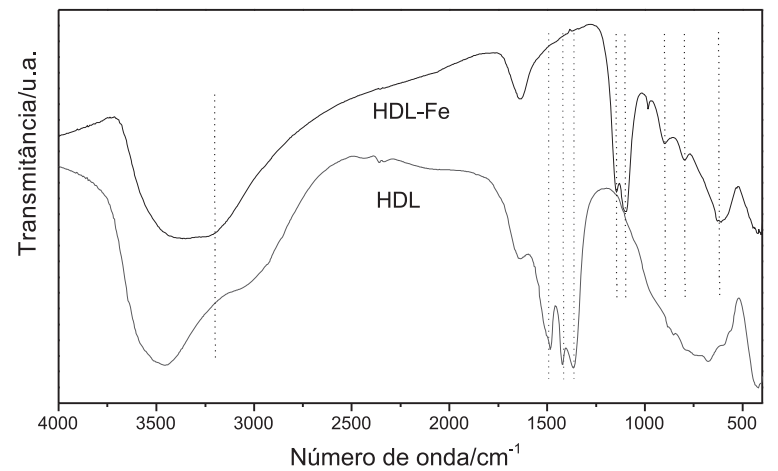

Figura 7. Espectro de infravermelho das amostras de HDL-Fe e HDL

As principais bandas de absorção de ânions foram observadas entre 1300 e $1800 \mathrm{~cm}^{-1}$. O ânion carbonato em um ambiente simétrico é caracterizado por uma simetria planar D3h, com três bandas de absorções ativas no IV, como no caso do ânion carbonato livre. $\mathrm{Na}$ maior parte dos compostos do tipo hidrotalcita as três bandas foram observadas a: $1350-1380 \mathrm{~cm}^{-1}\left(v_{3}\right), 850-880 \mathrm{~cm}^{-1}\left(v_{2}\right)$ e 670 $690 \mathrm{~cm}^{-1}\left(v_{4}\right)$. A presença de um ombro em torno de $1400 \mathrm{~cm}^{-1}$ ou de uma banda dupla na região de $1350-1400 \mathrm{~cm}^{-1}$ tem sido atribuída à redução da simetria do carbonato (sítio de simetria $\mathrm{C}_{2 \mathrm{v}}$ ) e à desordem natural no espaço interlamelar ${ }^{26}$. Miyata e colaboradores ${ }^{27}$ explicaram o abaixamento da simetria pela existência de dois tipos de coordenação do ânion carbonato no espaço interlamelar: complexo monodentado ou bidentado. No compósito HDL-Fe observa-se um deslocamento das bandas que pode ser atribuído a uma perturbação do ânion carbonato com o óxido de ferro.

\section{Adsorção do corante vermelho reativo}

Experimentos de adsorção do corante vermelho reativo em fase aquosa foram realizados em diferentes $\mathrm{pHs}$ (Figura 8). Em $\mathrm{pH}$ igual a 4, a hidrotalcita pura mostrou ser melhor adsorvente que o compósito. O principal motivo desta redução na capacidade de adsorção na hidrotalcita magnética é devida à presença de óxido de ferro, que tem uma menor capacidade de adsorção quando comparada com a da hidrotalcita (experimentos de adsorção conduzidos somente com o óxido de ferro mostraram baixa capacidade de adsorção). Em pH igual a 7, o compósito mostrou ser tão bom adsorvente quanto a hidrotalcita pura. Em pH igual a 9, o compósito mostrou ser melhor adsorvente que a hidrotalcita pura. Em trabalhos anteriores foi demonstrado ${ }^{10}$ que um compósito de zeólita:óxido de ferro é estável a $\mathrm{pHs}$ altos $(\mathrm{pH}=11)$; isto indica que o óxido de ferro é estável nos pHs estudados. Em pH igual a 9 a capacidade de adsorção decresce, provavelmente devido à hidrotalcita. Outro fator que pode influenciar é que em $\mathrm{pH}$ igual a 9 o meio possui uma maior concentração de $\left[\mathrm{OH}^{-}\right]$, que pode participar no processo de troca aniônica decrescendo, desta forma, a adsorção do corante aniônico.
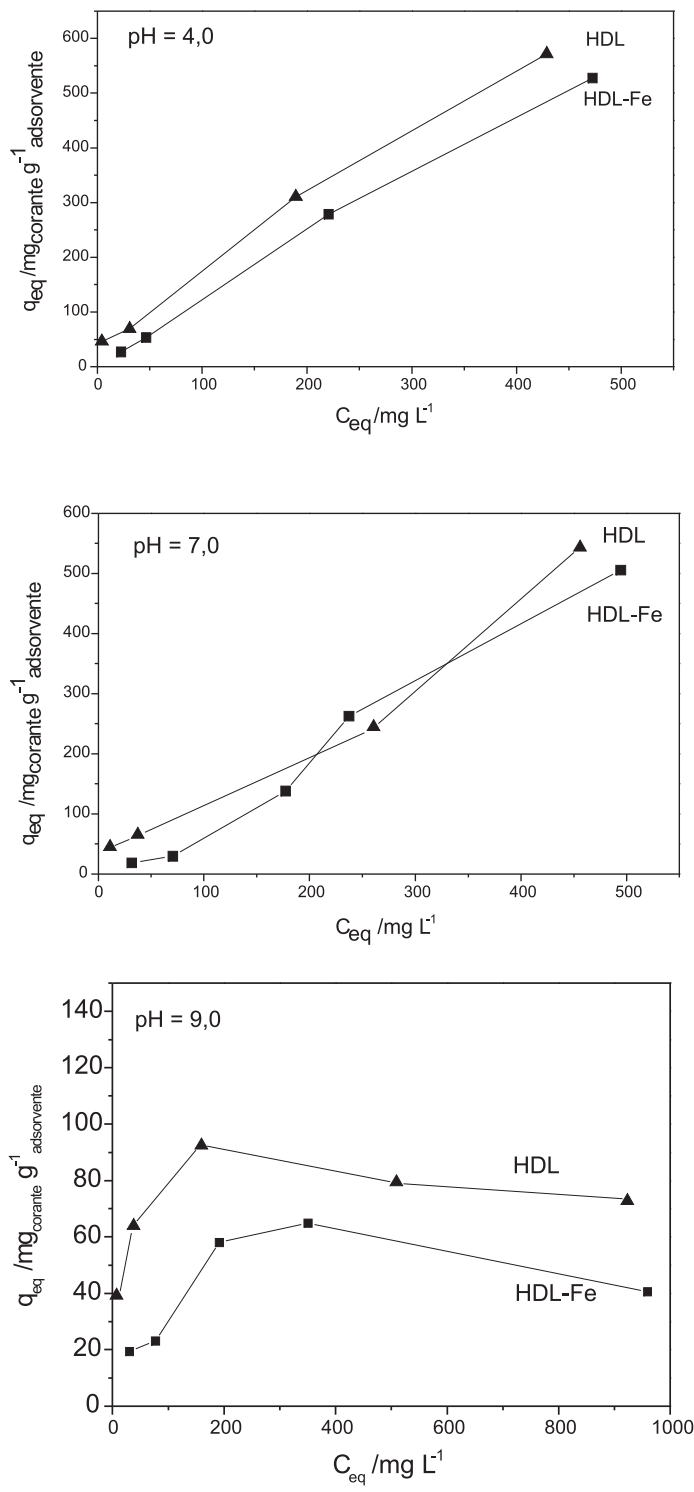

Figura 8. Isotermas de adsorção do corante aniônico em diferentes pHs

\section{Adsorção do cromato}

Foram realizados experimentos empregando soluções de íons dicromato. $\mathrm{O}$ íon dicromato em solução está em equilíbrio com o íon cromato, como representado abaixo:

$$
\mathrm{Cr}_{2} \mathrm{O}_{7}^{-2}+\mathrm{H}_{2} \mathrm{O} \leftrightarrow 2 \mathrm{CrO}_{4}^{-2}+2 \mathrm{H}^{+}
$$

$\mathrm{O}$ íon dicromato é laranja, enquanto que o íon cromato é amarelo. $\mathrm{O}$ experimentos foram realizados em diferentes $\mathrm{pHs}$, ácido, neutro e básico. Os resultados estão ilustrados na Figura 9. A concentração de cromato foi medida por absorção UV-visível no comprimento de onda de $370 \mathrm{~nm}$. Isso significa que o íon dicromato não foi medido.

$\mathrm{Em} \mathrm{pH}=4$, observa-se que o compósito adsorve maiores quantidades que a hidrotalcita pura, mesmo sendo constituído de $50 \%$ de óxido de ferro e $50 \%$ de fase hidrotalcita. A diminuição da concentração de íons cromato também ocorre devido ao aumento da concentração de $\mathrm{H}^{+}$, pois o equilíbrio se desloca para o íon dicromato (esquerda). 
Em $\mathrm{pH}=7$ podemos dizer que teremos uma mistura de íons dicromato e cromato e ambos são suscetíveis a serem adsorvidos pelo compósito e pela hidrotalcita. Talvez haja uma preferência pelo íon cromato, uma vez que este é menor e possuirá maior mobilidade. Neste caso, o equilíbrio se deslocaria para formar mais cromato e este seria, de novo, preferencialmente adsorvido. Como resultado ocorreria uma diminuição da concentração de íon cromato, como é evidenciado na Figura. Observa-se mais uma vez que o compósito adsorve maiores quantidades que a hidrotalcita pura.
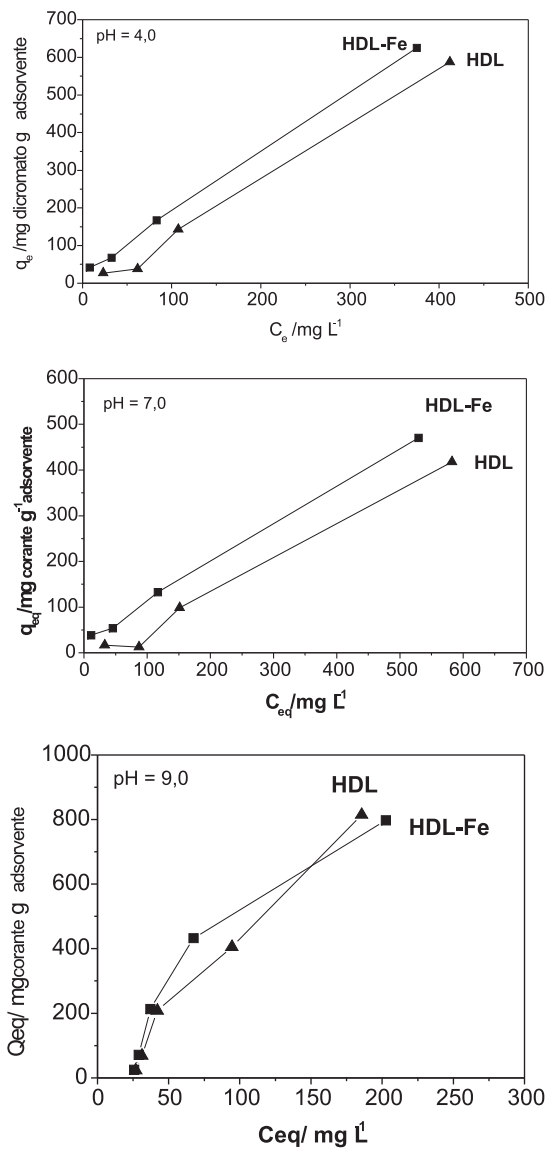

Figura 9. Isotermas de adsorção do íon cromato em diferentes $p H s$

Em $\mathrm{pH}=9$ teríamos uma maior concentração de hidroxilas, $\mathrm{OH}^{-}$, que neutralizariam os $\mathrm{H}^{+}$presentes; com a diminuição dos $\mathrm{H}^{+}$, o equilíbrio desloca-se para formar íons cromato (direita). $\mathrm{Na}$ Figura 9 observa-se um rápido decréscimo da concentração de cromato, devido a sua grande adsorção.

Os diferentes pHs, ácidos, básicos e neutros, foram empregados para avaliar a versatilidade do adsorvente. Acredita-se que em pHs muito ácidos ou muito básicos pode estar ocorrendo uma certa destruição da estrutura, como observado com outros materiais adsorventes ${ }^{9,10}$. Entretanto, o compósito continuou apresentando boas capacidades de adsorção nos diferentes pHs estudados.

\section{CONCLUSÃO}

As propriedades de adsorção das hidrotalcitas podem ser combinadas com óxidos de ferro para produzir adsorventes magnéticos. A preparação é simples e não requer nenhum reagente especial. Os compósitos mostraram alta capacidade de adsorção para diferentes contaminantes aniônicos em solução aquosa, não apresentando redução na capacidade de adsorção quando comparados com a hidrotalcita pura de partida.

\section{AGRADECIMENTOS}

À FAPERGS, URI - Campus Erechim e ao CNPq pelo auxílio financeiro, à Profa. N. R. C. F. Machado pelas análises de área superficial e ao Laboratório de Difração de raios-X - UFRGS pelas análises de DRX.

\section{REFERÊNCIAS}

1. Manju, G. N.; Gigi, M. C.; Anirudhan, T. S.; Indian J. Chem. Technol. 1999, $6,134$.

2. Lazaridis, N. K.; Asouhidou, D. D.; Water Res. 2003, 37, 2875.

3. Kovanda, F.; Kovassova, E.; Kolousek, D.; Collect. Czech. Chem. Commun. 1999, 64, 1517.

4. Goswamee, R. L.; Sengupta, P.; Bhattacharyya, K. G.; Dutta, D. K.; Appl. Clay Sci. 1998, 13, 21

5. Seida, Y.; Nakano, Y.; Water Res. 2002, 36, 1306

6. Booker, N. A.; Keir, D.; Priestley, A.; Rithchie, C. D.; Sudarmana, D. L.; Woods, M. A.; Water Sci. Technol. 1991, 123, 1703.

7. Sing, K. S.; Technol. Profile 1994, 21, 60.

8. Safarik, I.; Safarikova, M.; Buricova, V.; Collect. Czech. Chem. Commun. 1995, 60, 144.

9. Oliveira, L. C. A.; Rios, R. V. R. A.; Fabris, J. D.; Sapag, K.; Garg, V. K.; Lago, R. M.; Appl. Clay Sci. 2003, 22, 169.

10. Oliveira, L. C. A.; Petkowicz, D. I.; Smaniotto, A.; Pergher, S. B. C.; Water Res. 2004, 38, 3699.

11. Crepaldi, E. L.; Valim, J. B.; Quim. Nova 1998, 21, 300.

12. Pergher B. C.; Detoni, C.; Mignoni, M. L.; Materiais Laminares Pilarizados, Edifapes: Erechim, 2005, p. 34.

13. Vaccari, A.; Catal. Today 1998, 53, 41.

14. Roy, A. de; Forano, C.; El Malki, K.; Besse, J. P. H. E. Em Synthesis of Microporous Materials; Occeli, M. L.; Robson, H. E., eds.; Van Nostrand Reinhold: New York, 1992, vol II, p. 108.

15. Cardoso, L. P. Dissertação de Mestrado, Universidade de São Paulo, Brasil, 2002.

16. Kumbhar, P. S.; Sanchez-Valente, J.; Figueiras, F. J.; Chem. Soc., Chem. Commun. 1998, 1091.

17. Beres, A.; Palinko, I.; Kiricsi, I.; Nagy, J. B.; Kiyozumi, Y.; Mizukami, F.; Appl. Catal., A 1999, 183, 237.

18. Kagunya, W.; Hassan, Z.; Jones, W.; Inorg. Chem. 1996, 6, 134.

19. Manju, G. N.; Gigi, M. C.; Anirudhan, T. S.; Indian J. Chem. Technol. 1999, 6, 134.

20. Yamagishi, T.; Narita, E.; Nippon Kagaku Kaishi 2001, 12, 669.

21. Ambrogi, V.; Fardella, G.; Granolini, G.; Perioli, L.; Int. J. Pharm. 2001, $220,23$.

22. Vatier, J.; Ramdani, A.; Vitre, M. T.; Mignon, M.; Arzneim. Forsch. 1994, 44, 514.

23. Goswamee, R. L.; Sengupta, P.; Bhattacharya, K. G.; Dutta, D. K.; Appl. Clay. Sci. 1998, 13, 21.

24. Seida, Y.; Nakano, Y.; Water Res. 2002, 36, 1306.

25. Pérez, C. N.; Tese de Doutorado, Universidade Federal do Rio de Janeiro, Brasil, 2001.

26. Bastiani, R.; Dissertação de Mestrado, Universidade Federal do Rio de Janeiro, Brasil, 2001.

27. Miyata, S.; Clays Miner. 1975, 103, 369.

28. Bish, D. L.; Bridley, G. W.; Am. Mineral. 1977, 62, 458. 